\title{
Trace Element Analysis in Sera of Horses with Allergic Dermatitis and in Matched Healthy Controls with Special Attention to Zn, $\mathrm{Ni}$ and $\mathrm{Ti}$
}

\author{
Raija Hallamaa $^{*}\left(\mathbb{D}\right.$, Sirpa Peräniemi² $^{2}$ \\ ${ }^{1}$ Veterinary Clinic, Nummela, Finland \\ ${ }^{2}$ School of Pharmacy, University of Eastern Finland, Kuopio, Finland \\ Email: ^raija.hallamaa@elisanet.fi
}

How to cite this paper: Hallamaa, R. and Peräniemi, S. (2022) Trace Element Analysis in Sera of Horses with Allergic Dermatitis and in Matched Healthy Controls with Special Attention to $\mathrm{Zn}, \mathrm{Ni}$ and $\mathrm{Ti}$. Open Journal of Animal Sciences, 12, 129-144. https://doi.org/10.4236/ojas.2022.121010

Received: January 4, 2022

Accepted: January 24, 2022

Published: January 27, 2022

Copyright $\odot 2022$ by author(s) and Scientific Research Publishing Inc. This work is licensed under the Creative Commons Attribution International License (CC BY 4.0).

http://creativecommons.org/licenses/by/4.0/

\begin{abstract}
The most common allergic dermatitis of the horse is associated with hypersensitivity to insect bites. A purely hereditary-based background to this allergic pruritus has not been shown, and so far, it is not fully understood why some horses are more susceptible than others. Although altered zinc levels have been detected in many inflammatory and allergic disorders, changes in various trace elements have not been widely investigated in horses with allergic dermatitis. Therefore, the purpose was to analyse trace element profiles in the sera of 8 affected and 8 matched healthy horses and to further assess whether the profiles change after therapy of the affected animals. Sera were collected both before and after therapy of the eczema horses. Samples were analysed by inductively coupled plasma mass spectrometry for their iron $(\mathrm{Fe})$, copper $(\mathrm{Cu})$, zinc $(\mathrm{Zn})$, titanium $(\mathrm{Ti})$, vanadium $(\mathrm{V})$, chromium $(\mathrm{Cr})$, manganese $(\mathrm{Mn})$, cobalt $(\mathrm{Co})$ and nickel $(\mathrm{Ni})$ content. Concentrations of $\mathrm{Zn}$ and $\mathrm{Ni}$ were significantly lower in eczema than in healthy horses $(p=0.0089$ and $p=0.0018$, respectively). In addition, concentrations of $\mathrm{Fe}, \mathrm{Zn}$ and $\mathrm{Ni}$ displayed significant inverse associations with the severity of clinical signs ( $p=$ $0.0075, p=0.0397$ and $p=0.0011$, respectively). After a 4-week therapy, no significant differences were found between the groups. Concentrations of $\mathrm{Ti}$ were exceptionally stable both between the horses and over time. Horses with allergic dermatitis have alterations in their trace element profiles in comparison with healthy horses. Alterations seem to diminish when clinical signs are regressing.
\end{abstract}

\section{Keywords}

Culicoides, Equine Summer Eczema, Insect Hypersensitivity, Nickel, Zinc 


\section{Introduction}

Allergic dermatitis due to hypersensitivity to insect bites is one of the diseases profoundly impairing the quality of life of horses. This allergic disorder exhibits features similar to atopic dermatitis of humans, including intense and recurrent pruritus with IgE-mediated responses [1] [2]. Severity of clinical signs is related to the intensity of scratching and following skin lesions. This hypersensitivity affects horses recurrently during the summer months, when animals are exposed to biting insects, especially to species of Culicoides [3] [4] [5]. Therefore this disorder has been known also as summer eczema or insect bite hypersensitivity (IBH) [1] [4]. Although allergy to the salivary proteins of these midges is the main aetiological factor [4] [6], not all of the exposed horses become affected, in spite of the worldwide prevalence of Culicoides. Some horse breeds seem to be more sensitive to this pruritus than others [7] [8]. Several genetic regions possessing the immunological importance have been linked to insect hypersensitivity [9] [10] [11], and affected horses have shown variations in the amount and function of immune cells [1] [5] [12] [13]. However, a purely genetic background for this allergy has not been demonstrated and therefore, it is commonly recognized that this recurrent pruritus is a multifactor disease resulting from both hereditary and environmental predisposing factors [9] [14]. So far, it is obscure, why some horses are more susceptible to developing this dermatitis than others, even when they live in similar conditions. It has been shown that $\mathrm{Zn}$ plays a role in inflammatory and allergic manifestations, in both horses and humans [15]-[21] and is essential also for normal health [22] [23]. Zn plays a vital role in innate and adaptive immune responses and its intra- and extracellular concentrations are highly regulated according to the immune status [24] [25]. However, little is known about various trace elements and their possible association with this allergic disorder of horses. The purpose of this study was to assess the levels of nine trace elements in the sera of horses with allergic dermatitis and in their matched healthy controls by inductively coupled plasma mass spectrometry (ICP-MS) and to further determine whether trace element levels change after therapy of the affected horses. The analysed trace elements were iron $(\mathrm{Fe})$, copper $(\mathrm{Cu})$, zinc $(\mathrm{Zn})$, titanium $(\mathrm{Ti})$, vanadium $(\mathrm{V})$, chromium $(\mathrm{Cr})$, manganese $(\mathrm{Mn})$, cobalt $(\mathrm{Co})$ and nickel $(\mathrm{Ni})$. Of these, the elements with the most interesting or unexpected findings are discussed in more detail.

\section{Materials and Methods}

\subsection{Horses}

A total of 16 horses comprising 8 horses with allergic dermatitis and 8 matched healthy controls entered in this study. These horses were part of a series of earlier study that was focused on serum phospholipids, at which time also samples for the current study were collected [26]. Detailed information on the horses in the eczema and control groups is presented in Table 1. The diagnosis was based on typical clinical signs of insect hypersensitivity and was confirmed by a clinical 
Table 1. Horses with allergic dermatitis and their matched healthy controls.

\begin{tabular}{|c|c|c|c|c|c|c|}
\hline & \multicolumn{2}{|c|}{$\underline{\text { Gender }}$} & \multirow{2}{*}{$\begin{array}{l}\text { Age (years) } \\
\text { mean } \pm \text { sd } \\
\text { range }\end{array}$} & \multirow{2}{*}{$\frac{\underline{\text { Breed }}}{\text { Finnhorse }}$} & \multirow{2}{*}{$\begin{array}{l}\text { Icelandic } \\
\text { horse }\end{array}$} & \multirow{2}{*}{$\begin{array}{c}\text { Shetland } \\
\text { pony }\end{array}$} \\
\hline & q & 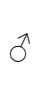 & & & & \\
\hline $\begin{array}{c}\text { Eczema horses } \\
n=8\end{array}$ & 6 & 2 & $\begin{array}{c}11.5 \pm 7.0 \\
4-23\end{array}$ & 5 & 3 & 0 \\
\hline $\begin{array}{c}\text { Control horses } \\
n=8\end{array}$ & 5 & 3 & $\begin{array}{c}13.5 \pm 8.6 \\
7-29\end{array}$ & 5 & 2 & 1 \\
\hline Total & 11 & 5 & $\begin{array}{c}12.5 \pm 7.7 \\
4-29\end{array}$ & 10 & 5 & 1 \\
\hline
\end{tabular}

examination performed by the author. Clinical signs were categorized as mild, moderate or severe depending on the intensity of pruritus and relating skin lesions and were correspondingly scored as 1,2 or 3. Signs were regarded as mild if pruritus was the only sign without skin lesions. Horses with pruritus and mild lesions in the mane, tail and/or body were graded as having moderate signs, while horses with pruritus and large skin lesions were classified as suffering from severe clinical signs. Horses without clinical signs were scored as 0 . Of the $8 \mathrm{ec}-$ zema horses, 4 horses showed mild and 4 moderate clinical signs when the study started. Only horses with typical clinical signs during thermal summer (mean 24-hour temperature $10^{\circ} \mathrm{C}$ or above) were included. Horses with signs of pruritus before or after this summer season were excluded, as were the horses that had been treated with antihistamines or glucocorticoids before this study started. Healthy horses without any history of allergic dermatitis were matched with breed, gender and age as closely as possible and they lived on the same farms and were fed with a similar fodder including mineral salts as their affected counterparts. Horses were enrolled from 3 separate farms, and the number of participated horses in these stables was 10, 4 and 2, respectively.

This study was approved by the Regional State Administrative Agency of Southern Finland (ESAVI/1016/04.10.07/2014). The current study was performed according to the guidelines of this ethics committee. Owners' signed informed consent for inclusion of their horses was obtained.

\subsection{Blood Samplings}

The first sample (indicated with 0 in Tables and Figures) for the trace element analysis was taken before the therapy and when the affected horses had shown typical clinical signs of allergic dermatitis for at least two weeks. The second sample (indicated with 4 in Tables and Figures) was collected when the eczema horses had been on therapy for 4 weeks. Samples were taken using $10 \mathrm{ml}$ plain vacuum tubes that were filled fully. Samples were kept at room temperature for at least 3 hours before harvesting to minimizing the effect on the sedimentation rate [27]. After subsequent erythrocyte clotting, sera were harvested without using centrifugation. Of the sera, $0.5 \mathrm{ml}$ were taken and stored at $-20^{\circ} \mathrm{C}$ until ana- 
lysed. Samples were collected from the matched healthy controls similarly and simultaneously and handled in the same manner. Syringes and blood-collection tubes used were taken from the same packages in both groups and over time. All samplings were performed during the summer season when both the eczema and healthy horses were simultaneously predisposed to biting insects.

\subsection{Therapy}

Eczema horses were treated with an oral administration of an autoserum preparation that was made from horse's own serum. A blood sample for autoserum preparation was drawn at the same time when the first sampling for the trace element analysis was performed. This autologous serum preparation contains major serum phospholipids present in the horse blood [28] and it was administrated once a day for 2 weeks, followed by a 1-week pause, after which horses were treated again for one week. Autoserum therapy is currently a usual method of treatment among Finnhorses in Finland [29]. Detailed information on the therapy is described earlier [29] [30]. Clinical signs were recorded both before and after the 4-week therapy by the author. The clinical condition was regarded as relieved when the signs became milder on the scale introduced above. Healthy control horses received no treatment.

\subsection{Trace Element Analysis}

Samples were analysed for their metal element content by inductively coupled plasma mass spectrometry (ICP-MS). The metals assayed were iron (Fe), copper $(\mathrm{Cu})$, zinc $(\mathrm{Zn})$, titanium $(\mathrm{Ti})$, vanadium $(\mathrm{V})$, chromium $(\mathrm{Cr})$, manganese $(\mathrm{Mn})$, cobalt $(\mathrm{Co})$ and nickel $(\mathrm{Ni})$.

\subsection{Statistical Analyses}

The Shapiro-Wilk test was performed to assess the normality of the concentration data. Data of separate trace elements were not uniformly normally distributed, thus both the means and the medians of separate metal concentrations were demonstrated. Because of the nonparametric distribution of the data, the Friedman test was used for pairwise comparisons of the concentrations between the matched groups and over time. The relationship between trace element concentrations and clinical signs before therapy was evaluated by Spearman's correlation test, likewise the association between the change of metal ion concentrations and clinical signs after therapy. Analyses were performed using statistical software StatsDirect (StatsDirect Ltd., Sale, Cheshire, UK). Two-sided $p$ values < 0.05 were considered significant.

\section{Results}

Since the concentration data were not uniformly normally distributed, the means, medians, lower and upper quartiles, and minimum and maximum levels are introduced of the trace elements analysed. The mean concentrations of trace ele- 
ments, both before and after therapy, are provided in Table 2, while Figure 1 and Figure 2 illustrate minimum, maximum and median levels, and lower and upper quartiles of the concentrations in the eczema and control groups. Concentrations of $\mathrm{Fe}, \mathrm{Cu}, \mathrm{Zn}$ and $\mathrm{Ti}$ were more abundant as compared with concentrations of $\mathrm{V}, \mathrm{Cr}, \mathrm{Mn}, \mathrm{Co}$ or $\mathrm{Ni}$ and are thus indicated with $\mathrm{mg} / \mathrm{L}$, whereas these minor concentrations of latter elements are indicated with $\mu \mathrm{g} / \mathrm{L}$ both in Table 2 and in Figure 2.

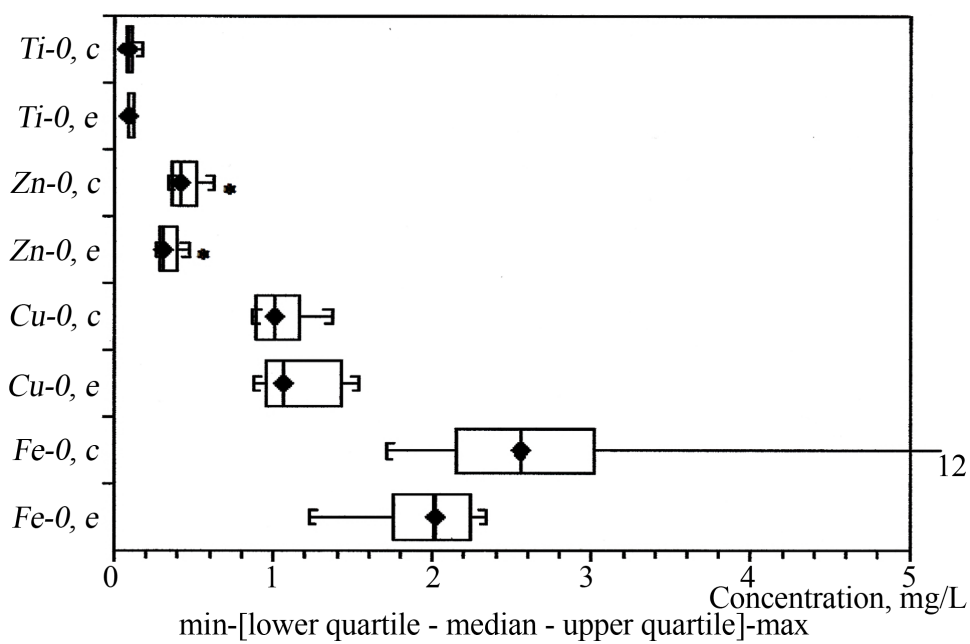

(a)

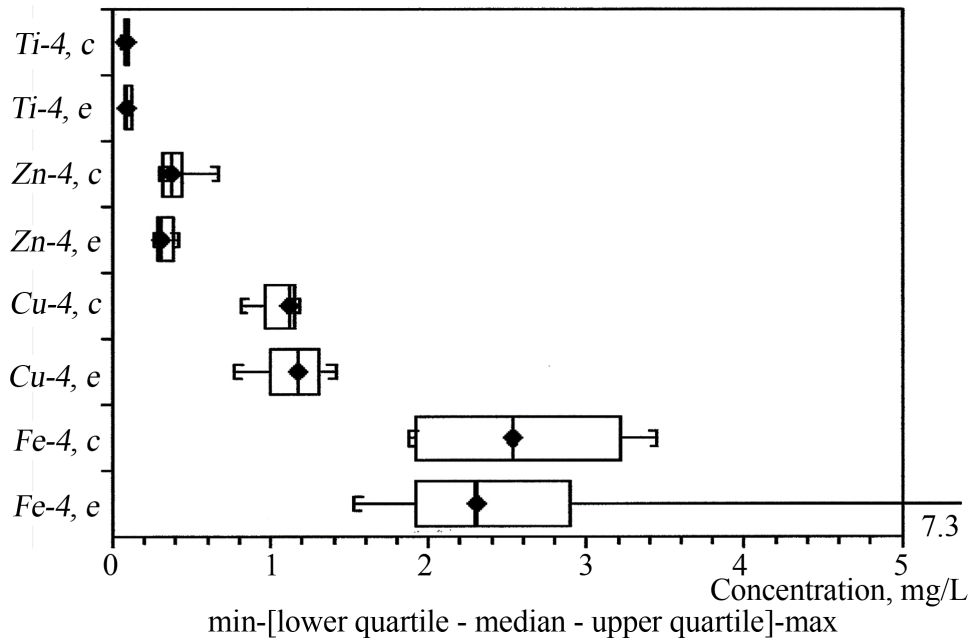

(b)

Figure 1. (a) Concentrations of the major elements with minimum, maximum and median levels in sera of horses with allergic dermatitis and healthy controls before therapy of eczema horses. Time of sampling is indicated with 0 and eczema and control groups with e and $c$, respectively. Trace elements analysed were iron $(\mathrm{Fe})$, copper $(\mathrm{Cu})$, zinc $(\mathrm{Zn})$ and titanium (Ti). ${ }^{*}$ Concentrations with statistically significant differences between the groups; (b) Concentrations of the major elements with minimum, maximum and median levels in sera of horses with allergic dermatitis and healthy controls after the 4-week therapy of eczema horses. Time of sampling is indicated with 4 and eczema and control horses with e and c, respectively. Trace elements analysed were iron $(\mathrm{Fe})$, copper $(\mathrm{Cu})$, zinc $(\mathrm{Zn})$ and titanium $(\mathrm{Ti})$. 
Table 2. Concentrations of 9 trace elements analysed in sera of horses with allergic dermatitis and matched healthy controls.

\begin{tabular}{cccccccccc}
\hline & \multicolumn{8}{c}{ Concentrations (mean $\pm \mathrm{sd})$} \\
\cline { 2 - 9 } & $\mathrm{Fe}$ & $\mathrm{Cu}$ & $\mathrm{Zn}$ & $\mathrm{Ti}$ & $\mathrm{V}$ & $\mathrm{Cr}$ & $\mathrm{Mn}$ & $\mathrm{Co}$ & $\mathrm{Ni}$ \\
& $\mathrm{mg} / \mathrm{L}$ & $\mathrm{mg} / \mathrm{L}$ & $\mathrm{mg} / \mathrm{L}$ & $\mathrm{mg} / \mathrm{L}$ & $\mu \mathrm{g} / \mathrm{L}$ & $\mu \mathrm{g} / \mathrm{L}$ & $\mu \mathrm{g} / \mathrm{L}$ & $\mu \mathrm{g} / \mathrm{L}$ & $\mu \mathrm{g} / \mathrm{L}$ \\
\hline Samples 0 & & & & & & & & & \\
Eczema horses & 1.97 & 1.16 & 0.34 & 0.10 & 1.19 & 15.2 & 29.9 & 2.41 & 16.1 \\
$\mathrm{n}=8$ & \pm & \pm & \pm & \pm & \pm & \pm & \pm & \pm & \pm \\
& 0.36 & 0.25 & 0.07 & 0.02 & 0.80 & 7.9 & 21.0 & 3.0 & 9.2 \\
Control horses & 3.66 & 1.04 & 0.44 & 0.10 & 2.33 & 38.1 & 36.2 & 18.3 & 209 \\
$\mathrm{n}=8$ & \pm & \pm & \pm & \pm & \pm & \pm & \pm & \pm & \pm \\
Samples 4 & 3.44 & 0.17 & 0.10 & 0.04 & 1.77 & 36.7 & 36.7 & 42.7 & 486 \\
& & & & & & & & & \\
Eczema horses & 2.88 & 1.15 & 0.33 & 0.10 & 1.25 & 63.9 & 26.6 & 4.21 & 19.3 \\
$\mathrm{n}=8$ & \pm & \pm & \pm & \pm & \pm & \pm & \pm & \pm & \pm \\
& 1.82 & 0.20 & 0.06 & 0.02 & 0.62 & 84.9 & 11.7 & 5.37 & 5.3 \\
Control horses & 2.54 & 1.07 & 0.40 & 0.08 & 1.66 & 23.8 & 26.0 & 15.3 & 25.2 \\
$\mathrm{n}=8$ & \pm & \pm & \pm & \pm & \pm & \pm & \pm & \pm & \pm \\
& 0.63 & 0.13 & 0.12 & 0.02 & 1.44 & 29.5 & 27.9 & 24.1 & 8.1 \\
\hline
\end{tabular}

The samples collected before therapy of eczema horses are indicated with 0 and the samples collected after a 4 -week therapy are indicated with 4 .

Before the start of the therapy, horses with allergic dermatitis had a significantly lower $\mathrm{Zn}$ concentration ( $p=0.0089$ ) than healthy horses (Figure 1(a)). Of the minor concentrations, $\mathrm{Ni}$ displayed a significantly more abundant concentration $(p=0.0018)$ in the sera of healthy than in the affected horses (Figure $2(a))$. One of the healthy horses showed an exceptionally abundant level of $\mathrm{Ni}$ $(1413 \mu \mathrm{g} / \mathrm{L})$ at the first sampling (Figure $2(\mathrm{a}))$, whereas at the second sampling the concentration was $21.2 \mu \mathrm{g} / \mathrm{L}$. However, $\mathrm{Ni}$ concentrations differed significantly between the groups even when the outliner and its matched counterpart had been excluded ( $p=0.0099, \mathrm{n}=7$ ). Concentrations of $\mathrm{Fe}, \mathrm{Cu}, \mathrm{Ti}, \mathrm{V}, \mathrm{Cr}, \mathrm{Mn}$ or Co did not differ significantly between the groups before the therapy (Figure 1(a) and Figure 2(a)). Concentrations of the minor metals seemed to diverge considerably between the horses (Figure 2(a)).

After the 4-week therapy of the affected horses, no statistically significant differences were found between the groups in either the concentrations of the major or minor metals (Figure 1(b) and Figure 2(b)). As shown in Table 2, at the second sampling the average $\mathrm{Zn}$ concentrations were lower in both groups; however, this drop was more obvious among the healthy horses. None of the trace element concentrations in the eczema or control group changed significantly between the samples collected before and after the therapy, although there were differences between the groups before the therapy. Concentrations of $\mathrm{Ti}$ seemed to be particularly constant both between the horses and over time (Table 2, Figure 1(a) and Figure 1(b)). In five of the 16 horses, Ti values were actually unchanged between both samplings. 


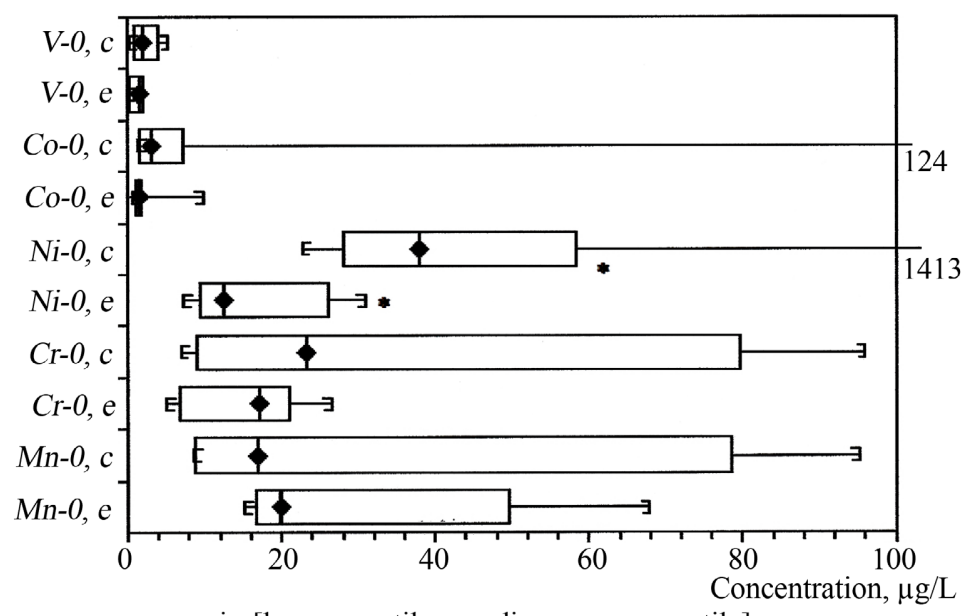

min-[lower quartile - median - upper quartile]-max

(a)

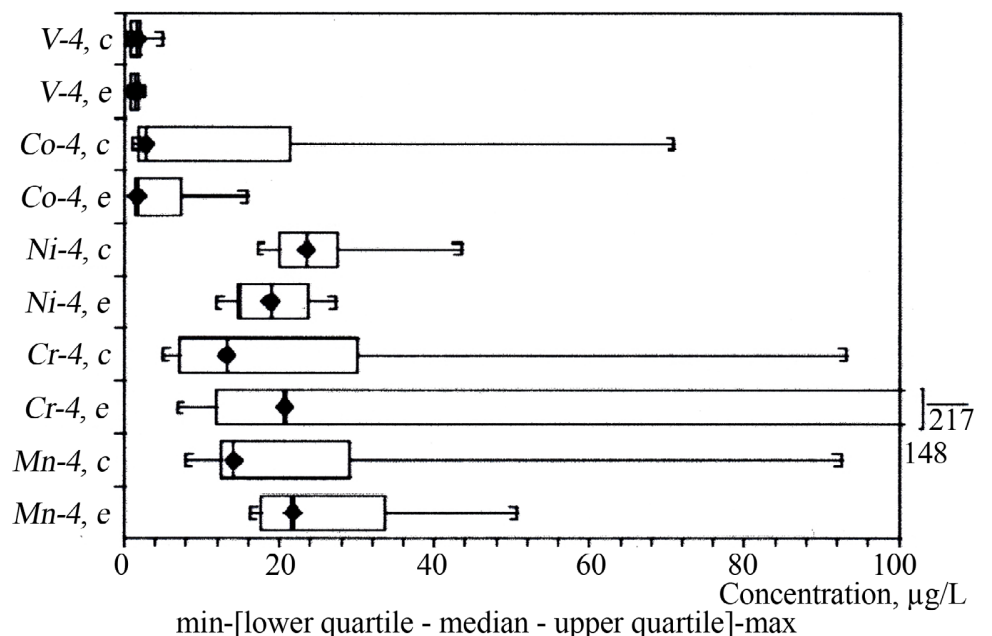

(b)

Figure 2. (a) Concentrations of the minor elements with minimum, maximum and median levels in sera of horses with allergic dermatitis and healthy controls before therapy of eczema horses. Time of sampling is indicated with 0 and eczema and control groups with e and c, respectively. Trace elements analysed were manganese (Mn), chromium (Cr), nickel $(\mathrm{Ni})$, cobalt $(\mathrm{Co})$ and vanadium $(\mathrm{V}) .{ }^{\star}$ Concentrations with statistically significant differences between the groups; (b) Concentrations of the minor elements with minimum, maximum and median levels in sera of horses with allergic dermatitis and healthy controls after the 4-week therapy of eczema horses. Time of sampling is indicated with 4 and eczema and control groups with e and c, respectively. Trace elements analysed were manganese $(\mathrm{Mn})$, chromium $(\mathrm{Cr})$, nickel $(\mathrm{Ni})$, cobalt $(\mathrm{Co})$ and vanadium $(\mathrm{V})$.

Before the start of the study, 4 horses suffered from mild clinical signs, while 4 horses showed moderate signs. Concentrations of $\mathrm{Fe}, \mathrm{Zn}$ and $\mathrm{Ni}$ displayed a significant inverse association with the severity of clinical signs (Table 3). After the 4-week autoserum therapy, signs had relieved in 5 horses, remained unchanged in 2, while in one horse clinical signs had been aggravated. However, the change in the $\mathrm{Fe}, \mathrm{Zn}$ or $\mathrm{Ni}$ concentrations did not correlate with the alterations in the clinical signs after therapy. 
Table 3. Correlations (r) between trace element concentrations and clinical signs of the horses $(n=16)$ before therapy.

\begin{tabular}{ccc}
\hline Trace element & Signs, $\mathrm{r}$ & $p$ value \\
\hline $\mathrm{Fe}$ & -0.6524 & $0.0075^{\star *}$ \\
$\mathrm{Cu}$ & 0.2177 & 0.4103 \\
$\mathrm{Zn}$ & -0.5217 & $0.0397^{\star}$ \\
$\mathrm{Ti}$ & 0.0843 & 0.7546 \\
$\mathrm{~V}$ & -0.2507 & 0.3433 \\
$\mathrm{Cr}$ & -0.2492 & 0.3491 \\
$\mathrm{Mn}$ & 0.0959 & 0.7214 \\
$\mathrm{Co}$ & -0.3916 & 0.135 \\
$\mathrm{Ni}$ & -0.7542 & $0.0011^{\star *}$ \\
\hline
\end{tabular}

${ }^{\star}$ Correlation is significant at 0.05 level (two-sided). ${ }^{\star *}$ Correlation is significant at 0.01 level (two-sided).

\section{Discussion}

Trace elements are classified by World Health Organization (WHO) as essential, probably essential or potentially toxic elements [23]. Of these, metabolic influences of the essential and potentially toxic elements are mostly well known in humans, whereas biological functions of the probably essential elements are so far inadequately defined, in both humans and animals [23] [31]. The purpose of the present study was to analyse trace element profiles in horses with allergic dermatitis and in their matched healthy controls and to further assess changes detected in profiles in response to therapy, but not the clinical efficacy of the therapy per se. Therefore, concentrations of nine trace elements, including both essential and probably essential elements, were analysed and their possible roles in this allergic disorder were evaluated.

Concentrations of $\mathrm{Zn}$ and $\mathrm{Ni}$ were significantly lower in horses with allergic dermatitis than in their matched healthy controls, whereas concentrations of Fe, $\mathrm{Cu}, \mathrm{Ti}, \mathrm{V}, \mathrm{Cr}, \mathrm{Mn}$ or Co did not differ between the groups. In previous studies, age or gender has exhibited no relation to the healthy horses' Zn levels in either the serum [17] [32] [33] or hair samples [34]. Usually, differing Zn concentrations have been associated with environmental factors such as feeding and dietary practices in various stables [16] [19] [33], although it has also been demonstrated that extra $\mathrm{Zn}$ supplemented in mineral salts did not significantly affect horses' serum levels [32] [35]. In order to avoid these confounding dietary factors, horses in the present study were matched also according to their feeding regimen and surroundings. Horses with severe clinical signs may spend less time for eating and thus show differing serum levels in comparison with healthy animals. However, none of the eczema horses showed signs that could have been classified as severe when this study started and horses were otherwise in a nor- 
mal physical condition without signs of emaciation. In addition, owners had not noticed any changes in eczema horses' appetite as compared with their controls. Therefore, it seems unlikely that the feeding habits could explain the detected differences between the healthy and affected horses.

It is generally accepted that trace element analyses are sensitive processes [36] [37] [38]. Results are influenced by various factors starting from the sampling and finally ending in interpretations. In our study, trace elements were analysed from the sera that were harvested without using centrifugation. Therefore, the absolute values of distinct concentrations in this study are not necessarily comparable to the results of previous studies in which centrifuged samples have been analysed. Our samples may have contained some blood cells, thus affecting concentrations of metal elements such as $\mathrm{Zn}$ and Fe that are found abundantly in the cells [16] [36] [39]. In addition, Zn levels have been shown to grow, when samples have been stored at room temperature longer than 3 hours [37] that was the minimum time for harvesting in the present study. In spite of these issues, serum Zn levels were clearly lower than in the previous study in which concentrations in the blood and centrifuged serum of healthy horses were assessed [40]. Above all, our study was designed to analyse the differences between the matched groups of horses, not to determinate the absolute values of concentrations in general.

It has been found earlier that in horses with Culicoides hypersensitivity $\mathrm{Zn}$ correlated significantly with the severity of clinical signs, although its plasma levels did not differ between the healthy and affected horses [19]. Similarly, a negative correlation between the $\mathrm{Zn}$ level and clinical signs was shown in our study in which the grading of clinical signs was virtually comparable with this earlier study [19]. These findings suggest that serum $\mathrm{Zn}$ is inversely linked to the clinical outcome of this allergic disorder.

Zn has a marked impact on functions of mast cells, especially on degranulation, and therefore disturbances in $\mathrm{Zn}$ homeostasis are inevitably conveyed to allergic responses [24]. In addition, $\mathrm{Zn}$ has been demonstrated to suppress allergic responses in human cells of atopic subjects by promoting the shift towards $\mathrm{T}$ helper 1 (Th1) cytokines and favouring regulatory $\mathrm{T}$ (Treg) cells [41]. Both these features have been related to the outcome of Culicoides hypersensitivity, healthy horses responding more commonly with Th1 skewing [5] and being more capable to enhance Treg cells than horses with insect hypersensitivity [1] [13]. It can therefore be assumed that $\mathrm{Zn}$ plays also a role in allergic skin responses in horses. The present study showed that $\mathrm{Zn}$ concentrations were significantly lower in eczema than in healthy horses and correlated with the severity of clinical signs. After a 4-week therapy, when clinical signs had relieved in 5 of the affected 8 horses, no significant difference was detected in $\mathrm{Zn}$ levels between the groups. After the therapy, however, a significant relationship could not be found between the changes in $\mathrm{Zn}$ concentrations and clinical status. Interestingly, Zn levels in both groups were actually lower than at the start of the study. This suggests that 
it is difficult to specify the beneficial or adequate $\mathrm{Zn}$ level in this particular disease since $\mathrm{Zn}$ participates in a multitude of signalling cascades, of which some display even opposing reactions depending on the $\mathrm{Zn}$ concentration and existing milieu [25]. Although Fe correlated significantly with clinical signs before the therapy, its concentration did not show significant differences between the groups at any phases of the study. It is well known that iron levels decrease in the blood during inflammation [42] and this is the most probable explanation for the inverse relationship between the Fe concentrations and severity of clinical signs.

Our earlier study on serum phospholipids in horses with allergic dermatitis showed that affected horses displayed significant alterations in their major serum phospholipids as compared with their matched healthy controls [26]. Phospholipids are bioactive molecules that operate in various inflammatory and cell signalling pathways [43] [44] [45]. After a 4-week autoserum therapy when clinical signs were regressing, concentrations of the differing phospholipids, phosphatidylcholine (PC) of glycerophospholipids and sphingomyelin (SM) of sphingolipids, were no longer distinguishable from the levels of the healthy horses [26]. In addition, changes in SM concentrations correlated significantly with alterations in the clinical status. Although both sphingolipids [46] and Zn [24] [41] are involved in allergic responses, a possible link between the serum phospholipids and $\mathrm{Zn}$ in horses with allergic dermatitis remains, for the present, obscure.

The significantly higher $\mathrm{Ni}$ concentration in the control horses in comparison with the eczema group at the first sampling and the inverse correlation between the Ni level and clinical signs were unexpected findings and to our knowledge have not been demonstrated earlier. Although Ni has been recognised as an essential or probably essential trace element detected in the nucleic acids of animals and humans, its biological role is still somewhat unclear [23] [47]. On the one hand, several Ni-dependent enzymes participating in various metabolic reactions have been identified in microbes and plants [31] [47] and on the other hand, the Ni excess is toxic to living organisms [23] [48]. Because biological functions of Ni have not yet been widely delineated in horses [32] [49], it was difficult to interpret the results of the present study. Sufficient amounts of Ni are usually ingested from the diet and drinking water [32] [50]. In humans, Ni values have ranged considerably between the subjects living in the same regions, even though the differences between the regions were not statistically significant [51]. This trace element is usually associated with its harmful effects such as contact dermatitis, but its use in arthroplasty and orthodontics as a component of stainless steel may also predispose to leaching with adverse impacts [38] [52] [53]. It has been demonstrated that $\mathrm{Ni}$ is leaching from orthodontic stainless steel ligatures when these components are incubated with artificial saliva, and the release increases over time [52]. Therefore exposure to this material, for example by using bits and watering vessels of poor quality, may predispose also 
horses to an excess of Ni. Although blood samples collected from various areas have shown alterations in horses' Ni concentrations, no significant differences have been detected in relation to the diet, environmental conditions or seasons [32] [49]. Recently, Ni has emerged as a potential doping substance in horses since it seems to possess similar stimulating effects on erythropoiesis that Co has [54] [55]. It has been demonstrated that serum levels of Ni increase significantly in healthy humans after a maximal exercise [56]. In the present study, one of the healthy horses showed an exceptionally high Ni concentration at the start of the study. Interestingly, this particular horse has moved restlessly just before the sampling which was recorded in the notes. At the second sampling, this horse was calm both before and during the blood sampling and its Ni concentration was in line with other healthy horses in this study.

It was noteworthy that both $\mathrm{Zn}$ and $\mathrm{Ni}$ correlated significantly with the severity of clinical signs and the concentrations were lower in the affected than in healthy horses at the start of the study, but not afterwards when clinical signs had become milder. In microorganisms, it has been shown that several Zn-related metalloenzymes are sensitive to minor amounts of $\mathrm{Ni}$, and it is also suggested that these trace elements compete for interactions with metalloenzymes [48]. Whether $\mathrm{Ni}$ is somehow coupled to $\mathrm{Zn}$ in allergic dermatitis of horses remains to be assessed in further studies.

Concentrations of $\mathrm{Ti}$ seemed to be particularly constant both between the horses and over time. So far, Ti is classified as a non-toxic element, since its biological role is still unclear [57] [58]. Ti accesses the body via food, but in humans it is accumulated also from cosmetics, paints and prostheses [57] [58]. Its serum levels have not been widely assessed either in horses or in humans [58] [59]. Minute amounts of Ti have been identified in the hair of healthy horses [59]. In the present study, however, considerable amounts of $\mathrm{Ti}$ were detected from the serum. As compared with the levels demonstrated in humans [56], concentrations in the horses were about five times as high as the concentrations detected in human serum. Transferrin, usually known as a transporter of iron, is suggested to participate also in trafficking of $\mathrm{Ti}$ [58]. With a synergistic action of citrate, transferrin regulates Ti metabolism between cells and the circulation [58]. In addition, Ti has been found in erythrocytes of cancer patients and also in neutrophils of patients with leukaemia, but not in blood cells of healthy controls [60] [61]. In cancer cells, it is suggested to have a role as a scavenger by deactivating intracellular hydrogen peroxide [60]. Even though Ti did not seem to be related to this allergic dermatitis of horses, its exceptionally unchangeable level in the sera pays attention to its actual function in the horse.

In conclusion, horses with allergic dermatitis show an altered trace element profile in their sera as compared with matched healthy controls. Concentrations of the different trace elements, $\mathrm{Zn}$ and $\mathrm{Ni}$, seem to inversely correlate with the clinical signs of horses. Even though the findings suggest an interaction between these trace elements and clinical outcome, further studies, especially on the role 
of $\mathrm{Ni}$, are needed to elucidate factors on the background of this harmful disease.

\section{Acknowledgements}

We thank Doc Arja I. Tervahauta for her cooperation and valuable advice with this study. We are grateful to the European Regional Development Fund (ERDF) Regional Council of Pohjois-Savs (projects A72184 and A72185) for the support of this study.

\section{Conflicts of Interest}

The authors declare no conflicts of interest regarding the publication of this paper.

\section{References}

[1] Heimann, M., Janda, J., Sigurdardottir, O.G., Svansson, V., Klukowska, J., von Tscharner, C., et al. (2011) Skin-Infiltrating T Cells and Cytokine Expression in Icelandic Horses Affected with Insect Bite Hypersensitivity: A Possible Role for Regulatory T Cells. Veterinary Immunology and Immunopathology, 140, 63-74. https://doi.org/10.1016/j.vetimm.2010.11.016

[2] Novak, N. and Leung, D.Y.M. (2011) Advances in Atopic Dermatitis. Current Opinion in Immunology, 23, 778-783. https://doi.org/10.1016/j.coi.2011.09.007

[3] Halldorsdottir, S., Larsen, H.J. and Mehl, R. (1989) Intradermal Challenge of Icelandic Horses with Extracts of Four Species of the Genus Culicoides. Research in Veterinary Science, 47, 283-287. https://doi.org/10.1016/S0034-5288(18)31247-5

[4] Langner, K.F.A., Jarvis, D.L., Nimtz, M., Heselhaus, J.E., McHolland, L.E., Leibold, W., et al. (2009) Identification, Expression and Characterisation of a Major Salivary Allergen (Cul s 1) of the Biting Midge Culicoides sonorensis Relevant for Summer Eczema in Horses. International Journal for Parasitology, 39, 243-250. https://doi.org/10.1016/j.ijpara.2008.06.008

[5] Meulenbroeks, C., van der Lugt, J.J., van der Meide, N.M.A., Willemse, T., Rutten, V.P.M.G. and Zaiss, D.M.W. (2015) Allergen-Specific Cytokine Polarization Protects Shetland Ponies against Culicoides obsoletus-Induced Insect Bite Hypersensitivity. PLoS ONE, 10, e0122090. https://doi.org/10.1371/journal.pone.0122090

[6] van der Meide, N.M.A., Roders, N., Sloet van Oldruitenborgh-Oosterbaan, M.M., Schaap, P.J., van Oers, M.M., Leibold, W., Savelkoul, H.F.J. and Tijhaar, E. (2013) Cloning and Expression of Candidate Allergens from Culicoides obsoletus for Diagnosis of Insect Bite Hypersensitivity in Horses. Veterinary Immunology and Immunopathology, 153, 227-239. https://doi.org/10.1016/j.vetimm.2013.03.005

[7] Björnsdottir, S., Sigvaldadottir, J., Broström, H., Langvad, B. and Sigurosson, A. (2006) Summer Eczema in Exported Icelandic Horses: Influence of Environmental and Genetic Factors. Acta Veterinaria Scandinavica, 48, Article No. 3. https://doi.org/10.1186/1751-0147-48-3

[8] Hallamaa, R.E. (2009) Characteristics of Equine Summer Eczema with Emphasis on Differences between Finnhorses and Icelandic Horses in a 11-Year Study. Acta Veterinaria Scandinavica, 51, Article No. 29. https://doi.org/10.1186/1751-0147-51-29

[9] Andersson, L.S., Swinbune, J.E., Meadows, J.R.S., Broström, H., Eriksson, S., Fikse, W.F., et al. (2012) The Same ELA Class II Risk Factors Confer Equine Insect Bite Hypersensitivity in Two Distinct Populations. Immunogenetics, 64, 201-208. 
https://doi.org/10.1007/s00251-011-0573-1

[10] Schurink, A., Wolc, A., Ducro, B.J., Frankena, K., Garrick, D.J. and Dekkers, J.C.M. (2013) Genome-Wide Association Study of Insect Bite Hypersensitivity in Two Horse Populations in the Netherlands. Genetics Selection Evolution, 44, 44-52. https://doi.org/10.1111/j.1365-2052.2012.02368.x

[11] Velie, B.D., Shrestha, M., Francois, L., Schurink, A., Tesfayonas, Y.G., Stinckens, A., Blott, S., Ducro, B.J., Mikko, S., Thomas, R., Swinburne, J.E., Sundqvis,t M., Eriksson, S., Buys, N. and Lindgren, G. (2016) Using an Inbred Horse Breed in a High Density Genome-Wide Scan for Genetic Risk Factors of Insect Bite Hypersensitivity (IBH). PLoS ONE, 11, e0152966. https://doi.org/10.1371/journal.pone.0152966

[12] Hamza, E., Wagner, B., Jungi, T.W., Mirkovitch, J. and Marti, E. (2008) Reduced Incidence of Insect-Bite Hypersensitivity in Icelandic Horses Is Associated with a Down-Regulation of Interleukin-4 by Interleukin-10 and Transforming Growth Factor- $\beta$ 1. Veterinary Immunology and Immunopathology, 122, 65-75.

https://doi.org/10.1016/j.vetimm.2007.10.018

[13] Hamza, E., Steinbach, F. and Marti, E. (2012) CD4+CD25+T Cells Expressing FoxP3 in Icelandic Horses Affected with Insect Bite Hypersensitivity. Veterinary Immunology and Immunopathology, 148, 139-144.

https://doi.org/10.1016/j.vetimm.2011.05.033

[14] van Grevenhof, E.M., Ducro, B., Heuven, H.C.M. and Bijma, P. (2007) Identification of Environmental Factors Affecting the Prevalence of Insect Bite Hypersensitivity in Shetland Ponies and Friesian Horses in the Netherlands. Equine Veterinary Journal, 39, 69-73. https://doi.org/10.2746/042516407X153020

[15] Ariaee, N., Farid, R., Shabestari, F., Shabestari, M. and Jabbari Azad, F. (2016) Trace Elements Status in Sera of Patients with Allergic Asthma. Reports of Biochemistry and Molecular Biology, 5, 20-25.

[16] Kolm, G., Helsberg, A. and Gemeiner, M. (2005) Variations in the Concentration of Zinc in the Blood of Icelandic Horses. Veterinary Record, 157, 549-551. https://doi.org/10.1136/vr.157.18.549

[17] Murase, H., Sakai, S., Kusano, K., Hobo, S. and Nambo, Y. (2013) Serum Zinc Levels and Their Relationship with Diseases in Racehorses. The Journal of Veterinary Medical Science, 75, 37-41. https://doi.org/10.1292/jvms.12-0122

[18] Seo, H-M., Kim, Y.H., Lee, J.H., Kim, J.S., Park, Y.M. and Lee, J.Y. (2017) Serum Zinc Status and Its Association with Allergic Sensitization: The Fifth Korea National Health and Nutrition Examination Survey. Scientific Reports, 7, Article No. 12637. https://doi.org/10.1038/s41598-017-13068-x

[19] Stark, G., Schneider, B. and Gemeiner, M. (2001) Zinc and Copper Plasma Levels in Icelandic Horses with Culicoides Hypersensitivity. Equine Veterinary Journal, 33, 506-509. https://doi.org/10.2746/042516401776254916

[20] Toyran, M., Kaymak, M., Vezir, E., Harmanci, K., Kaya, A., Ginis, T., et al. (2012) Trace Element Levels in Children with Atopic Dermatitis. The Journal of Investigational Allergology and Clinical Immunology, 22, 341-344.

[21] Youssef, M.A., El-Khodery, S.A. and Ibrahim, H.M. (2012) Antioxidant Trace Elements in Serum of Draft Horses with Acute and Chronic Lower Airway Disease. Biological Trace Element Research, 150, 123-129. https://doi.org/10.1007/s12011-012-9471-0

[22] Mulware, S.J. (2015) The Review of Nuclear Microscopy Techniques: An Approach for Non-Destructive Trace Elemental Analysis and Mapping of Biological Materials. Journal of Biophysics, 2015, Article No. 740751. https://doi.org/10.1155/2015/740751 
[23] Mehri, A. (2020) Trace Elements in Human Nutrition (II)-An Update. International Journal of Preventive Medicine, 11, 2.

[24] Vignesh, K.S. and Deepe, G.S. (2016) Immunological Orchestration of Zinc Homeostasis: The Battle between Host Mechanisms and Pathogen Defenses. Archives of Biochemistry and Biophysics, 611, 66-78.

https://doi.org/10.1016/j.abb.2016.02.020

[25] Maywald, M., Wessels, I. and Rink, L. (2017) Zinc Signals and Immunity. International Journal of Molecular Sciences, 18, Article No. 2222. https://doi.org/10.3390/ijms18102222

[26] Hallamaa, R. and Batchu, K. (2016) Phospholipid Analysis in Sera of Horses with Allergic Dermatitis and in Matched Healthy Controls. Lipids in Health and Disease, 15, 45-47. https://doi.org/10.1186/s12944-016-0209-4

[27] Baskurt, O.K., Farley, R. and Meiselman, H.J. (1997) Erythrocyte Aggregation Tendency and Cellular Properties in Horse, Human, and Rat: A Comparative Study. American Journal of Physiology, 273, 2604-2612.

https://doi.org/10.1152/ajpheart.1997.273.6.H2604

[28] Hallamaa, R.E., Batchu, K.C. and Tallberg, T. (2014) Phospholipids in Sera of Horses with Summer Eczema: Lipid Analysis of the Autoserum Preparation Used in Therapy. Equine Veterinary Journal, 46, 322-327. https://doi.org/10.1111/evj.12135

[29] Hallamaa, R. (2017) Phospholipids in Equine Summer Eczema and Its Therapy. Ph.D. Dissertation, Faculty of Veterinary Medicine, University of Helsinki, Helsinki. https://helda.helsinki.fi/handle/10138/216710

[30] Hallamaa, R.E. (2010) Autoserum Preparation in the Treatment of Equine Summer Eczema: Findings over 12 Years. Equine Veterinary Education, 22, 610-615. https://doi.org/10.1111/j.2042-3292.2010.00143.x

[31] Boer, J.L, Mulrooney, S.B. and Hausinger, R.P. (2014) Nickel-Dependent Metalloenzymes. Archives of Biochemistry and Biophysics, 15, 142-152. https://doi.org/10.1016/j.abb.2013.09.002

[32] Maia, L., de Souza, M.V., Fernandes, R.B.A., Fontes, M.P.F., Viana, M.W.S. and Luz, W.V. (2006) Heavy Metals in Horse Blood, Serum, and Feed in Minas Gerais, Brazil. Journal of Equine Veterinary Science, 26, 578-583.

https://doi.org/10.1016/j.jevs.2006.11.007

[33] Shawaf, T., Almathen, F., Meligy, A., El-Deep, W. and Al-Bulushi, S. (2017) Biochemical Analysis of Some Serum Trace Elements in Donkeys and Horses in Eastern Region of Kingdom of Saudi Arabia. Veterinary World, 10, 1269-1274. https://doi.org/10.14202/vetworld.2017.1269-1274

[34] Asano, R., Suzuki, K., Otsuka, T., Otsuka, M. and Sakurai, H. (2002) Concentrations of Toxic Metals and Essential Minerals in the Mane Hair of Healthy Racing Horses and Their Relation to Age. The Journal of Veterinary Medical Science, 64, 607-610. https://doi.org/10.1292/jvms.64.607

[35] Neustädter, L.T., Kamphues, J. and Ratert, C. (2018) Influences of Different Dietary Contents of Macrominerals on the Availability of Trace Elements in Horses. Journal of Animal Physiology and Animal Nutrition (Berl.), 102, e633-e640. https://doi.org/10.1111/jpn.12805

[36] Frank, E.L., Hughes, M.P., Bankson, D.D. and Roberts. W.L. (2001) Effects of Anticoagulants and Contemporary Blood Collection Containers on Aluminum, Copper, and Zinc Results. Clinical Chemistry, 47, 1109-1112. https://doi.org/10.1093/clinchem/47.6.1109

[37] Sampson, B. (1983) Automated Determination of Zinc and Copper in Plasma. The 
Journal of Automatic Chemistry, 5, 207-209. https://doi.org/10.1155/S1463924683000516

[38] Singh, V., Skipor, A.K., Selim, A.A. and Jacobs, J.J. (2018) Chromium and Nickel Concentrations in Subjects with a Stainless Steel Metal-on-Metal Cervical Disc Arthroplasty: Results from a Prospective Longitudinal Study with 7 Years Follow-Up. International Journal of Spine Surgery, 12, 460-468. https://doi.org/10.14444/5055

[39] Nelson, D.L. and Cox, M.M. (2008) Protein Function. In: Ahr, K., Ed., Principles of Biochemistry, WH Freeman and Company, New York, 153-163.

[40] Massanyi, P., Stawarz, R., Halo, M., Formicki, G., Lukac, N., Cupka, P., et al. (2014) Blood Concentration of Copper, Cadmium, Zinc and Lead in Horses and Its Relation to Hematological and Biochemical Parameters. Journal of Environmental Science and Health, Part A, 49, 973-979. https://doi.org/10.1080/10934529.2014.894322

[41] Rosenkranz, E., Hilgers, R-D., Uciechowski, P., Petersen, A., Plümäkers, B. and Rink, L. (2017) Zinc Enhances the Number of Regulatory T Cells in Allergen-Stimulated Cells from Atopic Subjects. European Journal of Nutrition, 56, 557-567. https://doi.org/10.1007/s00394-015-1100-1

[42] Borges, A.S., Divers, T.J., Stokol, T. and Mohammed, O.H. (2007) Serum Iron and Plasma Fibrinogen Concentrations as Indicators of Systemic Inflammatory Diseases in Horses. Journal of Veterinary Internal Medicine, 21, 489-494. https://doi.org/10.1111/j.1939-1676.2007.tb02995.x

[43] Fanning, L.B. and Boyce, J.A. (2013) Basic Science for the Clinician: Lipid Mediators. Annals of Allergy, Asthma \& Immunology, 111, 155-162. https://doi.org/10.1016/j.anai.2013.06.031

[44] Stables, M. and Gilroy, D. (2011) Old and New Generation Lipid Mediators in Acute Inflammation and Resolution. Progress in Lipid Research, 50, 35-51. https://doi.org/10.1016/j.plipres.2010.07.005

[45] van Meer, G. (2005) Cellular Lipidomics. The EMBO Journal, 24, 3159-3165. https://doi.org/10.1038/sj.emboj.7600798

[46] Kendall, A. and Nicolaou, A. (2013) Bioactive Lipid Mediators in Skin Inflammation and Immunity. Progress in Lipid Research, 52, 141-164. https://doi.org/10.1016/j.plipres.2012.10.003

[47] Ragsdale, S.W. (2009) Nickel-Based Enzyme Systems. Journal of Biological Chemistry, 284, 18571-18575. https://doi.org/10.1074/jbc.R900020200

[48] Macomber, L. and Hausinger, R.P. (2011) Mechanisms of Nickel Toxicity in Microorganisms. Metallomics, 3, 1153-1162. https://doi.org/10.1039/c1mt00063b

[49] de Souza, M.V., Fontes, M.P.F. and Fernandes, R.B.A. (2014) Heavy Metals in Equine Biological Components. Revista Brasileira de Zootecnia, 43, 60-66. https://doi.org/10.1590/S1516-35982014000200002

[50] Martiniaková, M., Omelka, R., Grosskopf, B., Chovanková, H., Massányi, P. and Chrenek, P. (2009) Effects of Dietary Supplementation of Nickel and Nickel-Zinc on Femoral Bone Structure in Rabbits. Acta Veterinaria Scandinavica, 51, Article No. 52. https://doi.org/10.1186/1751-0147-51-52

[51] Bank-Nielsen, P.I., Long, M. and Bonefeld-Jørgensen, E.C. (2019) Pregnant Inuit Women's Exposure to Metals and Association with Fetal Growth Outcomes: ACCEPT 2010-2015. International Journal of Environmental Research and Public Health, 16, Article No. 1171. https://doi.org/10.3390/ijerph16071171 
[52] Olszewska, A., Hanc, A., Baralkiewicz, D. and Rzymski, P. (2019) Metals and Metalloids Release from Orthodontic Elastomeric and Stainless Steel Ligatures: In Vitro Risk Assessment of Human Exposure. Biological Trace Element Research, 196, 646-653. https://doi.org/10.1007/s12011-019-01936-8

[53] Pantuzo, M.C.G., Zenóbio, E.G., Marigo, H.A. and Zenóbio, M.A.F. (2007) Hypersensitivity to Conventional and to Nickel-Free Orthodontic Brackets. Brazilian Oral Research, 21, 298-302. https://doi.org/10.1590/S1806-83242007000400003

[54] Ho, E.N.M., Chan, G.H.M., Wan, T.S.M., Curl, P., Riggs, C.M., Hurley, M.J., et al. (2014) Controlling the Misuse of Cobalt in Horses. Drug Testing and Analysis, 7, 21-30. https://doi.org/10.1002/dta.1719

[55] Thevis, M., Machnik, M., Schenk, I., Krug, O., Piper, T., Schänzer, W., et al. (2016) Nickel in Equine Sports Drug Testing-Pilot Study Results on Urinary Nickel Concentrations. Rapid Communications in Mass Spectrometry, 30, 982-984. https://doi.org/10.1002/rcm.7528

[56] Otag, A., Hazar, M., Otag, I., Gurkan, A.C. and Okan, I. (2014) Responses of Trace Elements to Aerobic Maximal Exercise in Elite Sportsman. Global Journal of Health Science, 6, 90-96. https://doi.org/10.5539/gjhs.v6n3p90

[57] Saghiri, M.A., Orangi, J., Asatourian, A., Sorenson, C.M. and Sheibani, N. (2016) Functional Role of Inorganic Trace Elements in Angiogenesis Part III: (Ti, Li, Ce, As, $\mathrm{Hg}, \mathrm{Va}, \mathrm{Nb}$ and $\mathrm{Pb}$ ). Critical Reviews in Oncology/ Hematology, 98, 290-301. https://doi.org/10.1016/j.critrevonc.2015.10.004

[58] Tinoco, A.D., Saxena, M., Sharma, S., Noinaj, N., Delgano, Y., Quinones Gonzalez, E.P., et al. (2016) The Unusual Synergism of Transferrin and Citrate in the Regulation of Ti(IV) Speciation, Transport, and Toxicity. Journal of the American Chemical Society, 138, 5659-5665. https://doi.org/10.1021/jacs.6b01966

[59] Asano, K., Suzuki, K., Chiba, M., Sera, K., Asano, R. and Sakai, T. (2006) Relationship between Trace Elements Status in Mane Hair and Atrial Fibrillation in Horse. The Journal of Veterinary Medical Science, 68, 769-771. https://doi.org/10.1292/jvms.68.769

[60] Johansson, E. and Lindh, U. (1984) Leukemia-Its Manifestation in the Microelement Profile in Individual Blood Cells as Determined in the Nuclear Microprobe. Nuclear Instruments and Methods in Physics Research B, 3, 637-640. https://doi.org/10.1016/0168-583X(84)90452-X

[61] Johansson, E., Lindh, U., Johansson, H. and Sundström, C. (1987) Micro-PIXE Analysis of Macro- and Trace Elements in Blood Cells and Tumors of Patients with Breast Cancer. Nuclear Instruments and Methods in Physics Research B, 22, 179-183. https://doi.org/10.1016/0168-583X(87)90321-1 